\title{
Art of Engagement: Visual Art of Thailland in Global Contexts
}

\section{Thanom Chapakdee}

Srinakharinwirot University Thailand

\begin{abstract}
This paper on the topic of Art of Engagement: Visual Art of Thailand in Global Contexts, attempts to explore that "global contexts" is transformed because of the impacts rapid change in economics, politics, society and culture. Globalization based on the notion of Global art and transform Thai art scene into the state of international art movement such as Installation art, Performance art, Community art, i.e. these movement becomes the mainstream of art since 1980s. This kind of movement which artist has created the art objects, space, time and sphere as a model of sociability which audiences can participate with people in community as relational art practice. The relational art becomes the space of exchange and participants can share experienced of taste, aesthetic, criticism which it's related to art objects and sphere of community. This paper will explains that relational art is in the process of art of engagement. That is why art has become the community engagement which art objects and practical based are of the relational art and relational aesthetics.
\end{abstract}

Keywords: community art, relational art

\section{INTRODUCTION}

It seems that nowadays the word 'culture' is excessively used in a very superficial way. People use it just to appear fashionable and to follow the trend that calls for culture at all levels. Indeed, the meaning and context of culture are very important to people living in a society. Within culture, the arts rely on specific contexts to serve as a starting point. In the art creation of today's artists, it's crucial that artists learn and apprehend the origin and the development of culture which is part of their art practice. Integration of cultural traits such as stories, legends, tradition or people's way of life; artistic practice and creativity, results in artworks which overlap with the original culture.

Before going into the details of the integration concept, one of the most popular ideas incorporating the interdisciplinary approach in contemporary society, or how artists should use it in their practice, I'd like to talk about 'collaboration' and 'public art.' If artists take these ideas to use in their work without limitation, unexpected results from the audience will inevitably be produced. This is because public art is created from the involvement between artists and the public. So, it's important that the artists be aware of their own creativity, which might be new to the community. Also, artists should be concerned about how concepts of integration and collaboration are practically implemented. For example if artists don't learn about all aspects of a certain community they may risk introducing 
something unacceptable into that community. In the end, they will generate misunderstandings about the role of art.

In the context of today's contemporary art, there are many artists who claim that they use the integration form as their artistic creation process. However they ignore the basic spirit of integration and collaboration with the community. In most cases, artists consider themselves superior to the community. This egocentric attitude is always a contemporary problem in many contexts not only in the art field. However, this is one cause which pushes the public away from art movements, creating a gap between art and the public.

According to my observation of contemporary art movements in Thailand for more than two decades, most artists are only concerned about artwork achievement. They neglect how the process and purpose of the work affects the community. Many outdoor sculptures or public art pieces are ignored, because they have no connection to the community in which they were placed. Time and time again public art exhibitions are created by artists and viewed almost exclusively by artists and those in the art scene but not the general public.

What is the notion of public art and what are the factors which cause the problems in collaboration between art and community? The organizers of public art events seem to manage all parts of the activity, without paying attention to the importance of the community's way of life. This still occurs even though they are well aware that collaboration is the process of working between at least two parties. If community involvement is not encouraged, failure in communication with the community will be the consequence. Although the artists/organizers or sponsors might announce the 'success' of an activity, the outcome is still the work of artists alone. The community doesn't have any involvement.

The main cause of this problem is that the artist community rarely interacts with other communities. Artists tend to limit their focus to creating art for the sake of art only. However, when the time comes to create an activity with the community outside of the art world, artists, curators and art organisers are frequently using the power of networking and mobilising the masses to call for cooperation. Without having a real understanding of the local contexts of that community, artists pretentiously refer to the cultural benefits and improved living standard which community members will receive from art.

Remember that art is a freely born phenomenon. However, it comes from the processes of life, culture, traditions and beliefs of a particular social community. So, the 'language' of public art reveals the cultural context or discourse existing in that community. On the contrary, all that has happened under the definition of public art in Thai society has become the personal expression of an individual who used the public space. And this event became unconnected and misplaced, crudely made to that community. Therefore, it's not uncommon that public art is only a superficial phenomenon that remains outside of the interest of the community. 
Now, public art becomes unacceptable to communities as it is reduced to objects which artists put into the community made up entirely from a personal narrative or solely for decoration.

Back to our starting point, 'what are the factors which cause problems in the collaboration between art and community?' As we know, in collaboration, artists first need to know how to present themselves and which strategies they will use in order to engender the participation of the community. Artists must learn through experience as well. Even if it is an abstract matter, once a concept of creating art in public space comes to mind, artists or activity creators really need to learn every aspect of that community as clearly as possible in a concrete way. Then they will understand the culture, environments and public spaces in that community. An important factor is that different aspects need to be respected. It is not just an empty space to put something as each space has a story and memory related to its people.

Certainly, in any integration and collaboration with community, to create art activities and art work, we have to think about the project feasibility, the fragility of cultural space, traditions, the community's beliefs as well as unexpected errors. So, an important point to know is that culture and way of life are changing all the time. Still, artists should not push things to make a breakthrough brusque change. Involvement which comes from integration and collaboration needs to involve brain storming the real powers of the community and respecting the fundamental concepts of each side. If these ideas can be implemented there will be fewer problems.

NavinRawanchaikul is an artist who created a public art programme, which consists mostly of public involvement. He organized various kinds of activities which allowed different groups of people to interact with his work. One thing which appeared to be his trademark was the use of many types of vehicles as part of his work. The vehicles served as mobile art galleries, offering the general public an opportunity to experience art while commuting in their daily life. The use of vehicles demonstrates the concept of introducing art into public space in a dynamic, concrete way. Navin's mobile gallery comprised of taxis, tuktuks, bicycles and scooters. In his Fly with Me to Another World Project (henceforth Fly with $\mathrm{Me}$ ), not only the work itself is movable, but his art exhibition space is also migratory. For 10 years Navin has created vehicles carrying his 'artistic luggage' to interact with communities around the world. I believe that the exploration of the 'nomad'has become the main concept of his work which has been meaningful to his artistic practice. So, it's not strange that Navin was impressed by the life of Inson Wongsamand made a revision of Inson's journeys, an extraordinary story that very few artists and travelers achieve.

InsonWongsam became a legend of Thai art. He was born in 1934 in Lamphun, a historical mid-size town in northern Thailand. Having completed a 5-year course in printmaking and sculpture at Silpakorn University in Bangkok, he was 
awarded a scholarship, which enabled him to travel all over Thailand. He spent a year exploring Thailand and produced paintings and woodcuts of great charm and originality. In 1961, he held his solo exhibition at the Gallery of Tourism Organisation of Thailand in Bangkok. His travels in Thailand were a mere forerunner of a far more ambitious plan.

Inson always dreamt of travelling around the world and experiencing other cultures, especially Italy - the land of Art and the native country of Prof. Silpa Bhirasri ${ }^{1}$ for whom Inson had great respect. However, due to the lack of substantial financial means, he was unable to immediately realize his dream. At the age of 28, Inson held an auction of his works to raise money for the trip. $\mathrm{He}$ then presented his project to travel around the world to Berlie

Jucker, the representative company for Italian scooters in Thailand. The company decided to support Inson by offering him a Lambretta scooter to use on his journey. Esso contributed funds for his fuel. Friends and peers from university donated work of art to be sold by auction to provide additional support.

Inson left Thailand in the middle of May 1962, one week after the death of his beloved mentor Prof. Silpa, to whom he had made the solemn promise to abide by his teachings and to always strive to benefit society. Equipped with a few clothes and some finished works of art, he travelled through India, Pakistan, Iran, Turkey and Greece, until he arrived in Italy in August 1963. Throughout the 16 months of his journey, Inson exhibition his works many times and drew a lot of interest from art critics and the international press. After a successful solo exhibition at a renowned gallery in Florence, the home town of Prof. Silpa, Inson continued his dream to travel the world before finding himself in the Big Apple where he realized great success and became the first internationally acclaimed Thai artist.

In 1974, after 12 years on the road, Inson decided to return his roots. He came back to Lamphun and built a small studio in the forest and lived like a farmer, slept at sunset and rose with the dawn. He wanted no distractions of any kids. He did not even have any books. He wanted to draw and make wood sculpture and to increase his knowledge of herbal medicine. He became a friend to the villagers but they could not understand why a man who had travelled the world and lived in a great city like New York should want to return to the wilds.

With respect for his lifelong contribution to the arts and culture of Thailand, InsonWongsam was honoured with the distinction of a National Artist of Thailand ${ }^{2}$ in 1999. This famous award has not changed the simple life of Inson. He still lives in the village, creating his arts and supporting cultural activities in his community continuously.

1 Prof.SilpaBhirasri (CorradoFeroci, 1893-1962), the Italian born, founder of Silpakorn University -the first Art University in Thailand.

2 Inson Wongsam was appointed by Office of the National Culture Commission to be a National Artist of Thailand in Visual Arts (Sculpture) for the year 1999. The King of Thailand bestows this honour to National Artists as a lifetime achievement award. 
The most striking period in Inson's journeys was taken as the source of work by Navin. By doing this, Navin, a generation later than Inson, has represented the continuation of Thai art. It is the case where up until now Inson has not shared his history, however he is proud to be talked about by others.

Following Navin'sFly with Me, Inson has gained the attention of the international art press and his work has been exhibition in several international locations from 1999-2001. Various editions of the project are permanent collections at important contemporary art institutions and galleries ${ }^{3}$ Just as Inson returned home after a long journey, in February 2004, Navin finally brought Fly with Me back to Lamphun, Inson's native town. A year- long exhibition was set up at the Hariphunchai National Museum in Lamphun. Instead of having a mere exhibition, Navin was determined to develop a year of activities that encouraged local participation and collaboration among people and organisations across fields and generations. A series of community outreach activities have been conducted throughout the year including workshops, performances, exhibitions and public talks. Ending the project by linking the local with the international, parallel to the journeys of Inson and Navin, the Public art In(ter)vention Symposium was organised as a platform to discuss interdisciplinary art practices in communities.

With regard to the variety of Fly with Me activities that Navin included in a yearlong project, I believe that he picked up the concept of Inson 'stopping over' in places during the journey. There were times when Inson exhibition the works he took along with him, and also sold some to contribute to living costs. I think it's the point that inspired Navin to create activities with many communities in Lamphun, where his exhibition about Inson was held. Therefore, the Fly with Mehas become the representation of the accumulated work of the original discourse, the expression of InsonWongsam, and the new discourse, that of Navin and his collaborators who created another layer to add to Inson's journey within their own surroundings.

The art of Navin is site-specific, where the creative process; its content and form, is presented through a wide variety of media and activity. His works always relates to people's daily life and collaboration plays an important role in his creation. Through Fly with Me activities. Navin collaborated with more than 20 organisations, from museums to temples, with governmental offices as well as NGOs, with artists and non-artists across all generations, local and international. The project itself provided an alternative model of how artists can 'collaborate' with the 'other' (outside the art word). At the same time, it also stood as a platform for research about public art practice and the response from the local community regarding contemporary art. 
'Vehicles' which move and carry Navin's art objects constantly go forward and stop over at public areas in different communities. Navin's 'caravan' continues to tell new stories about Arts for he is an expert in public art who can wisely made a synthesis from multidisciplinary fields which become his strategic creative artistic practice. Moreover, he knows how to organise things by using different kinds of art strategies. Having seen the integration concept embedded in art creative process of Navin from his beginnings to his Fly with $\mathrm{Me}$, I am completely convinced that integration ideology is the key theory which drives the artist to a world of variety, where accumulated facts and realities lie. And, it serves as an important conditional opportunity for artists to perceive, share ideas and interact with communities in various dimensions.

Surviving and at the same time maintaining the integration concept in art creative practice is not easy because the essence of each discipline is difficult to integrate. Moreover, to be able to work in different community spaces, artists must also respect and trust the norms of that community. Otherwise, the concept of integration could destroy the community's way of life.

99, Foundazione Sandretto Re Rebaundengo per L'Arte, Guanrene, Italy (1999); Satani Gallery, 31 ${ }^{\text {st }}$ Art Basel (Art Statement), Basel, Switzerland (2000, Baloise Art Prize); Le Consortium, Dijon, France (2000); Fuori Uso (The Bridges) Art on the Highway,Piazza Unione, Pescara, Italy (2000); The Gift of Hope, Museum of Contemporary Art, Tokyo, Japan (2000-2001); II Dono, Pallazzodelle Papesse, Centro Arte Contemporanea, Siena, Italy (2001); Navin RawanchaikulE Adel Abdessemed,Laura Pecci Gallery, Milan, Italy (2001); Chateau Scoterus, Fourchambault, France (2001). Selected Fly with Me to Another World editions are held in permanent collections at the Foundazione Sandretto Re Rebaundengo per L'Arte, Guanrene, Italy; Le Consortium, Dijon, France; Stedelijk Museum voor Actuele Kunst (S.M.A.K), Ghent, Belgium; and ARCO Foundation, Madrid, Spain.

\section{REFERENCES}

Bourriaud, Nicolas. 2002. Relational Aesthetics. France: les presses du reel.

Chiu Mellissa and Genocchio, Benjamin. 2010. Contemporary Asian Art. London: Thames \& Hudson.

Clark, John. 1998. Modern Asian Art. Sydney: Craftsman house.

Identities versus Globalization? (Cat). 2004. Chaing Mai: Heirich Boll Foundation. Poshyananda, Apinan. 1992. Modern Art in Thailand. Singapore: Oxford UniPress. Rawanchaikul, Navin. 2006. Fly with Me to Another World. Thailand:Fly with Me to Another World Project.

Rawanchaikul, Navin. 2008. Navin'sS ala. Chaing Mai: Navin Production. 


\section{NavinRawanchaikul's Work's "Fly with Me to Another World"}
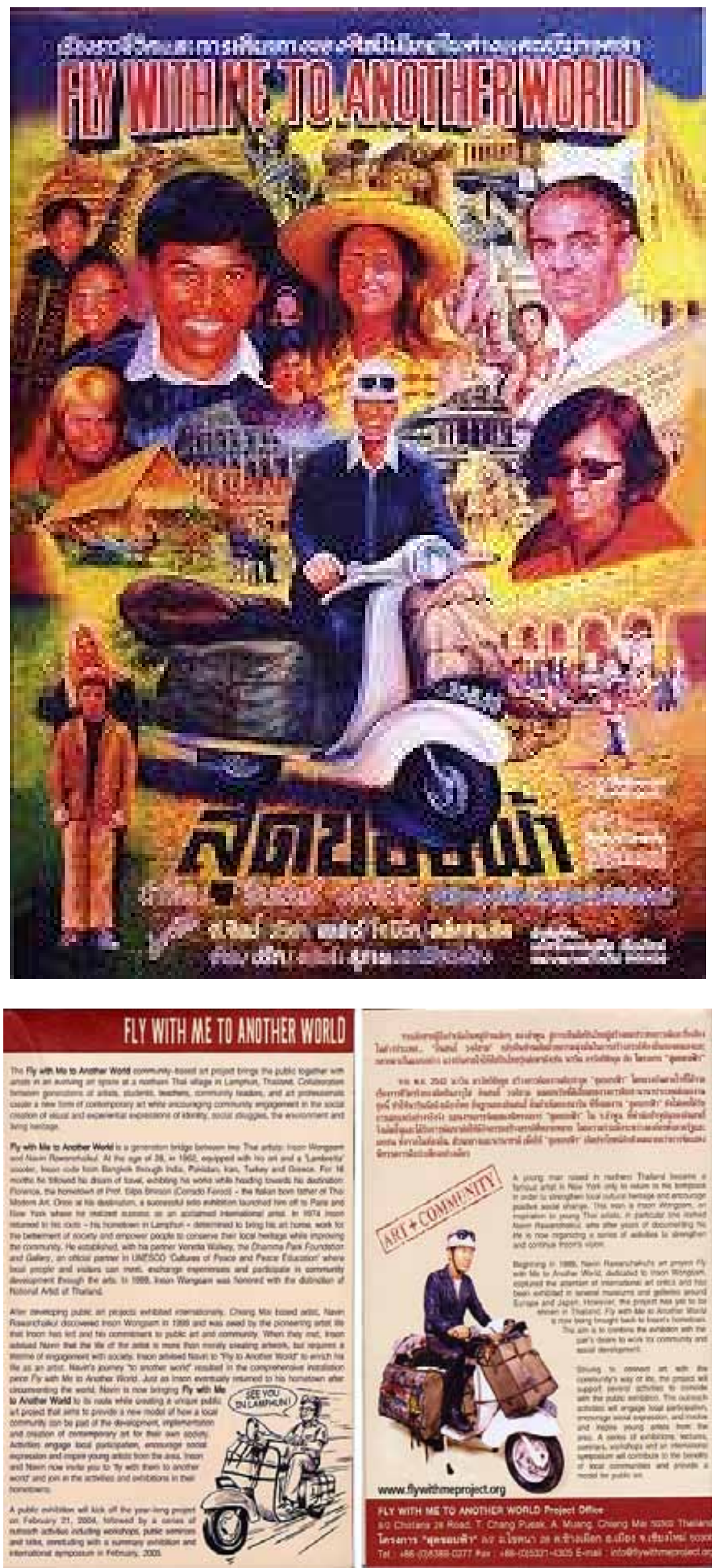
NavinRawanchaikul's Work's "Fly with Me to Another World'
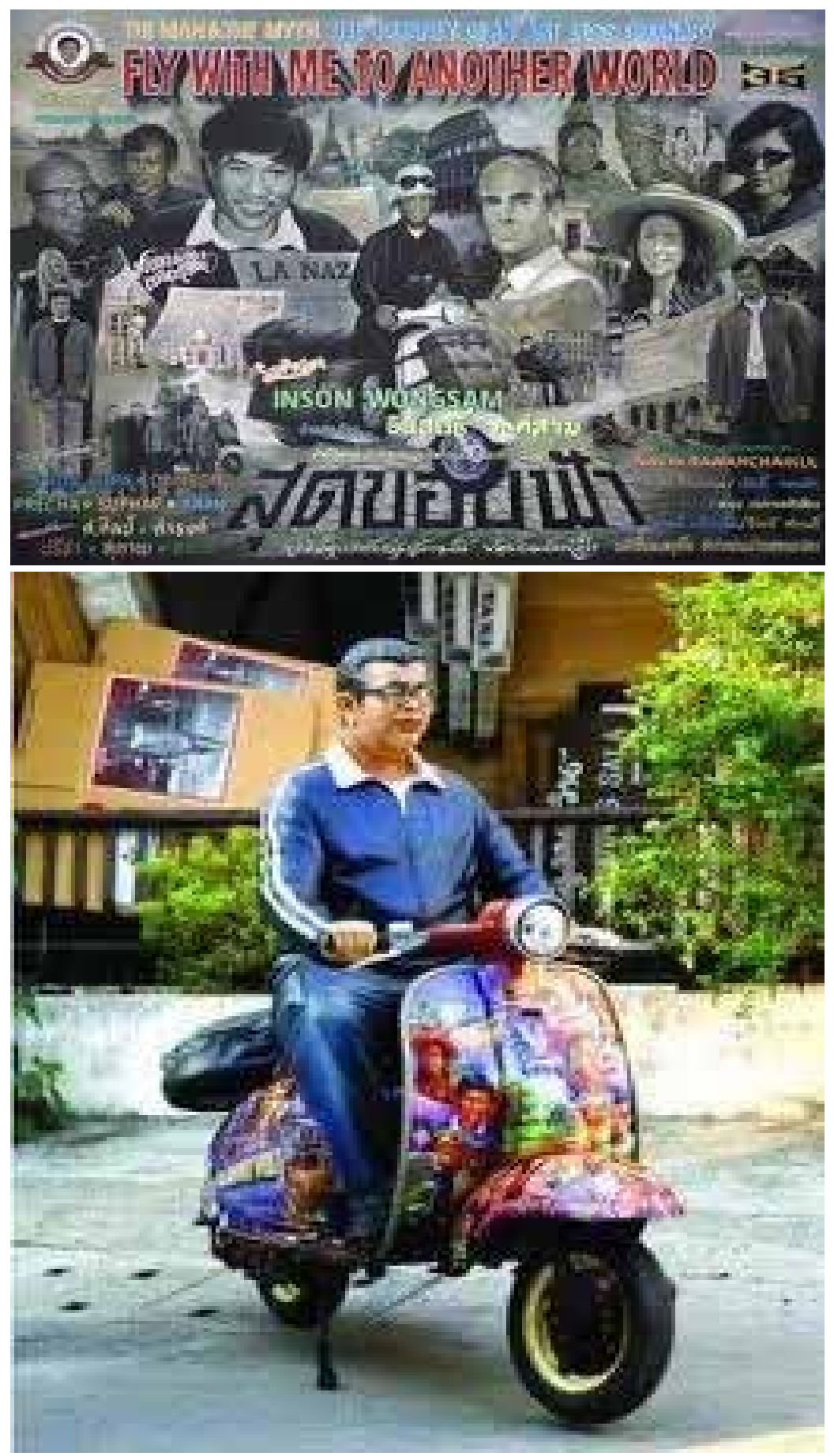
NavinRawanchaikul's Work's "Fly with Me to Another World"

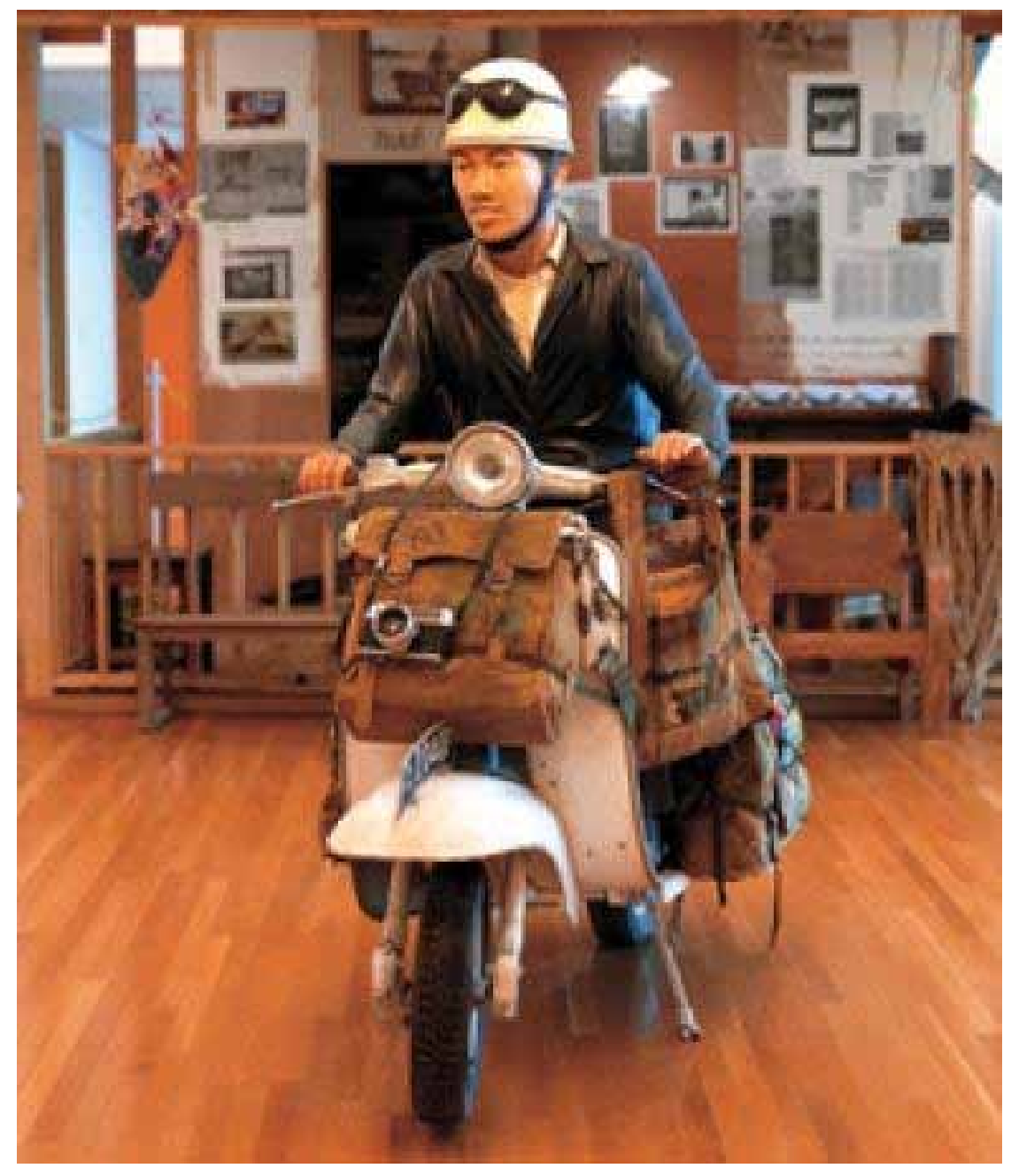

